\title{
FEAST 2020: A conference 2.0
}

\author{
Charlotte Hauser (IJN, ENS, CNRS) \\ charlotte.hauser@live.fr
}

\begin{abstract}
FEAST is a regular forum to discuss formal and experimental approaches to sign language grammar. Beside the years when TISLR, the world-wide academic event on sign language research that takes place every three years, is organized, FEAST is normally held every year in the format of an in-presence conference spanning over two or three days, with keynote presenters, non-parallel main sessions and poster sessions. The languages of the conference are ASL/International Sign for sign language and English. In 2020, due to the COVID-19 outbreak in Asia, FEAST was first moved from Hong Kong to Paris with the intent of keeping it an in-presence event and finally held as a fully online event. The paper describes the measures put in place to organize an online Deaf friendly scientific conference.
\end{abstract}

Keywords: conference, organization, analysis, accessibility, guidelines

\section{Introduction}

The eighth meeting of the "Formal and Experimental Advances in Sign language Theory" (FEAST) colloquium had to take place in Hong-Kong in June 2020. Unfortunately, right after the call for abstract deadline passed mid-February, the increase of COVID-19 cases in Asia forced the local organizers to withdraw. When contacted by the scientific committee, sign language researchers in Paris offered to host the FEAST 2020 event. With the idea of keeping it an in-presence event, FEAST was then co-organized by the Ecole Normale Supérieure/CNRS (IJN), the Université de Paris /CNRS (LLF and Labex-EFL), and the Université Paris 8/CNRS (SFL). Mid-March, with the worldwide lock-down, the whole conference had to be re-imagined. It was finally held online on June 23-25, 2020. The conference had English and ASL/International Sign as official languages and the whole budget was used to provide both offline translation and online interpretation. The conference included 10 oral/signed presentations and 12 posters with a recommended watching program starting on Tuesday, June 23rd and ending on Thursday, June 25th. You can consult the conference's website here and see the program here. Around 700 people registered to the conference with an average attendance during question sessions of 70 people. More details about attendance and the results from the follow-up survey we distributed to participants can be found at the end of the paper.

In what follows, we describe what went well and what went wrong in the organization of the conference so that it can be used for future reference to organize online Deaf friendly scientific events. 


\section{Previous events and lessons learned}

The conference format was of course the first challenge. How should we proceed to have a fully Deaf-friendly online conference? On which platform should we host it? How could we conduct Q/A sessions? Should it be all live, in real-time (i.e. synchronous) or should it be asynchronous such that presenters pre-record their presentations in video format and attendants are free to watch them whenever they feel like it?

We benefited a lot from the experience of conferences which moved from in-presence to online in April 2020, right when the FEAST local organizers were about to decide on the format of the conference: CUNY (Human Sentence Processing Conference) and GLOW (Generative Linguistics in the Old World). The organizing committees of the two conferences adopted rather opposite strategies: CUNY was held live, following a pre-established program, and only the poster sessions were asynchronous, while GLOW was completely asynchronous and spread over a two weeks period.

CUNY organized all the synchronous talks and Q/A sessions on a video-conference platform, Zoom webinars, ${ }^{1}$ and hosted poster sessions on a research-focused online archive, OSF. $^{2}$ All the access links could be found on their website. Through the use of Zoom webinars, questions could only be asked using the written chat and they were visible only to the host and panelist. Participants had no control over their sound and video, so a session's host had to select questions and unmute the correct person for each question (see Figure 1).

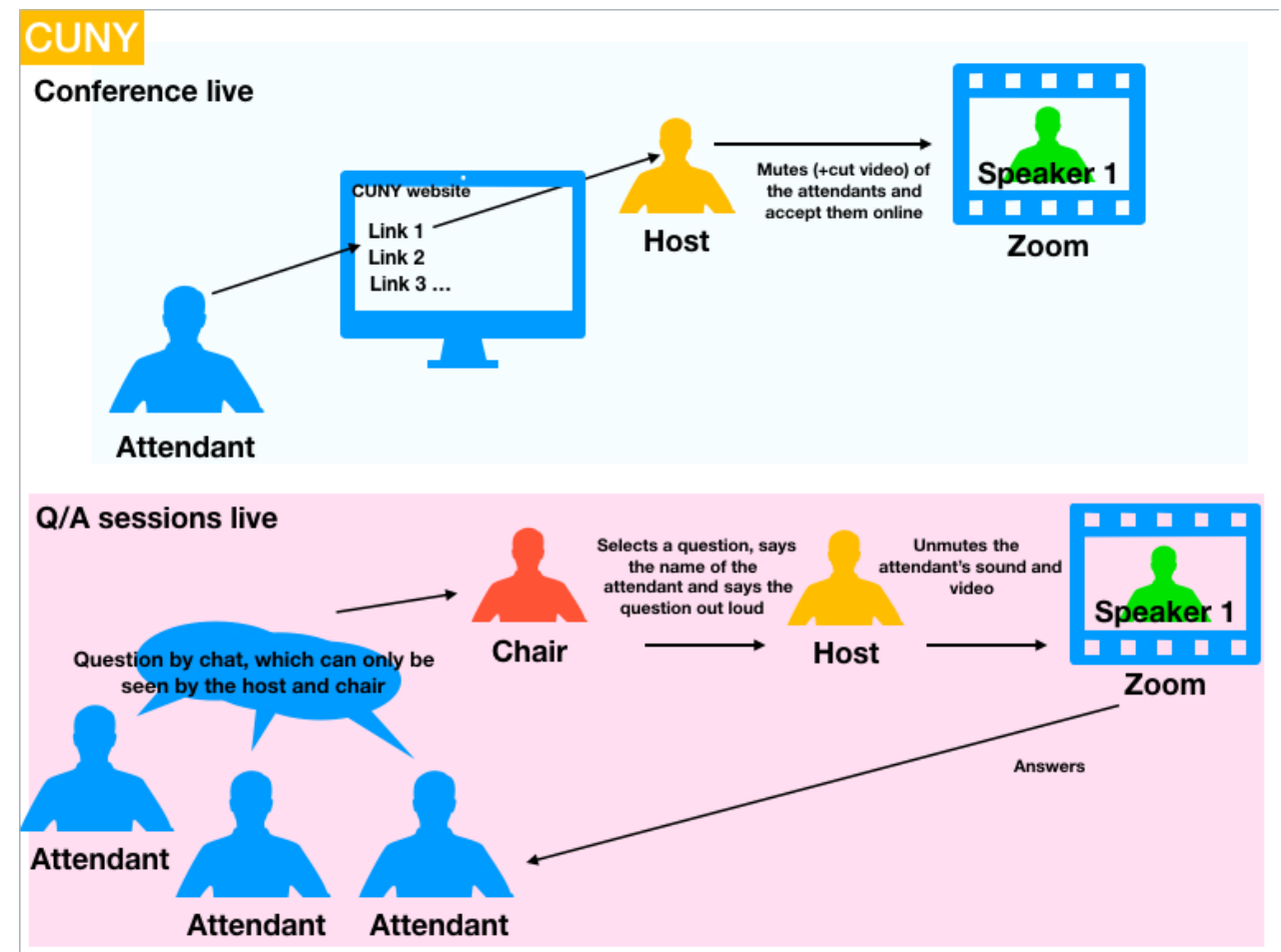

Figure 1: Schematic representation of the CUNY conference organization, during talks and their Q/A sessions.

\footnotetext{
${ }^{1}$ https://zoom.us

2 https://osf.io
} 
For posters, the PDF version of the poster and a video-presentation each were put in an OSF folder and discussions could be held through the chat integrated on the website (see Figure 2). All the details of the CUNY organization can be found in this very detailed blog article.

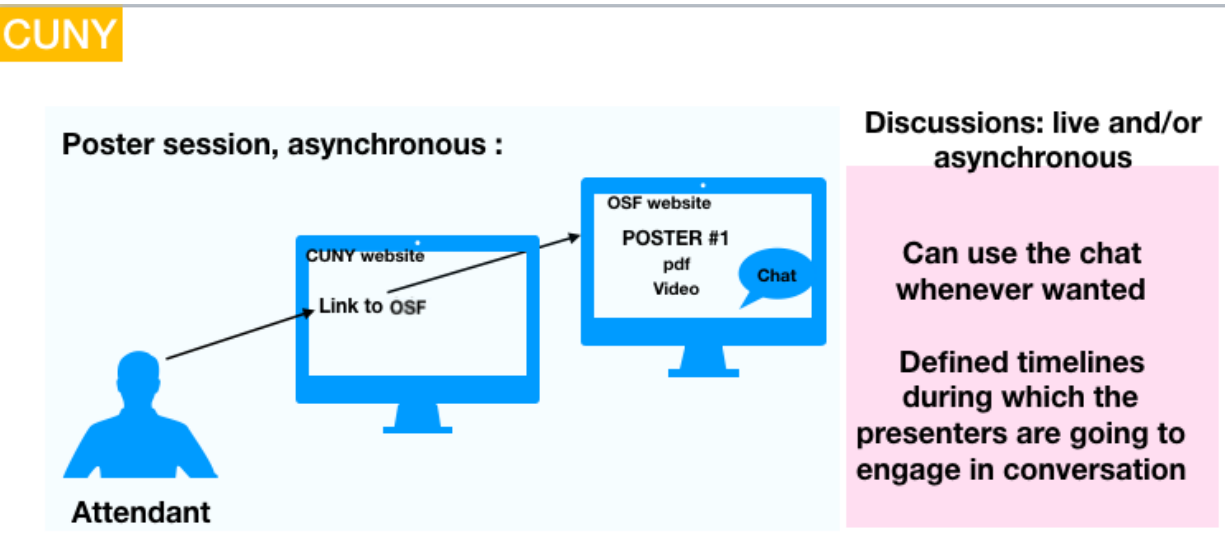

Figure 2: Schematic representation of the CUNY poster sessions organization.

At the end of the conference, the organizing committee collected feedback from attendants showing that participants preferred synchronous talks and felt as engaged in CUNY's online conference as they would have been in an on-site setting. The aspects which could have been improved were poster sessions and social events, at which attendants did not engage much.

GLOW asked all presenters to put their slides, talk videos and/or posters on their dedicated OSF folder; discussions happened solely through the written chat implemented on the OSF platform. In this conference, presenters had to manage their own pages and had the opportunity to add as much material as needed (see Figure 3).

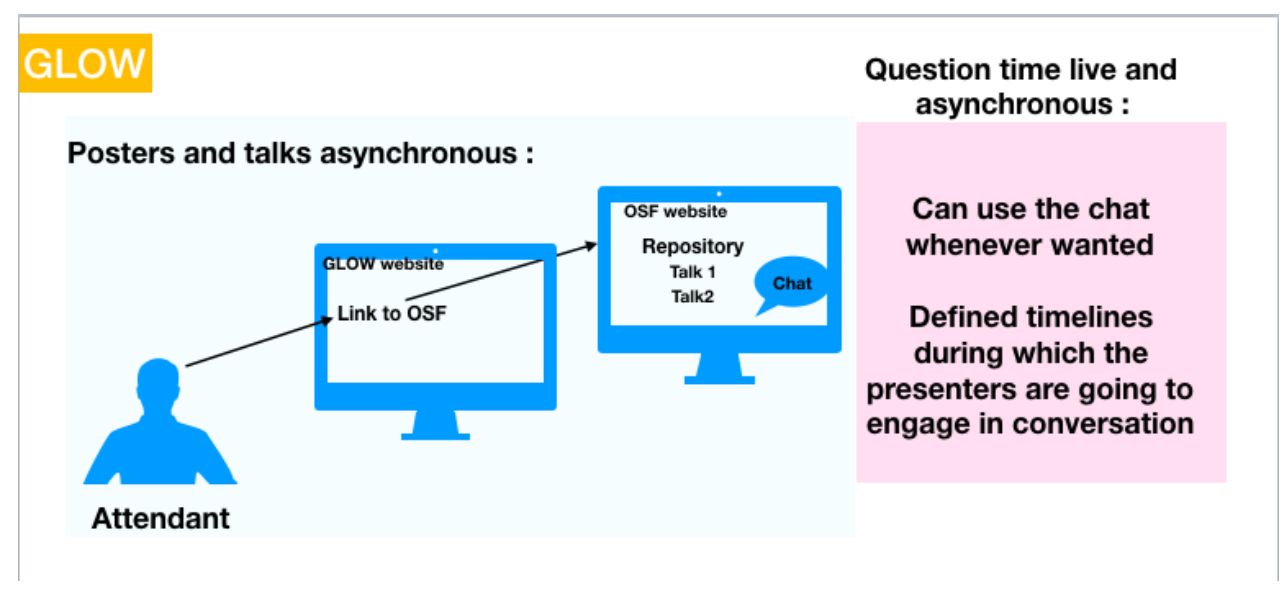

Figure 3: Schematic representation of the GLOW conference organization. 
Talk videos had to be around 45 minutes long. Just like CUNY's poster sessions, there were time slots indicated in GLOW's program to mention live-interaction opportunities, that is, times at which the presenter would be guaranteed to be online to answer to chat questions, without mediation or chairing involved. Apart from these slots, presenters had a two weeks period over which they could discuss their research with attendants. This extended period allowed people from all over the world to participate to the conference, irrespective of their time zone.

The GLOW organizing committee did not officially collect feedback from their attendants and participants. We did however collect informal feedback from some of them who felt that the all-asynchronous format did not give a conference-like feeling. Attendants went directly to the pages presenting topics they were already familiar with. It also seems that people felt a bit lost in the large quantity of information and did not engage as much as they would have done in an on-site format.

From these two events we learned that: 1) having a fully asynchronous event is not very engaging, 2) we need to have one website with the whole conference searchable (instead of multiple platforms), 3) the Q/A sessions has to be held live to allow engagement.

In addition to these, FEAST also has additional requirements related to the fact that it is a bilingual-bimodal conference where all main events are offered in two languages, ASL/Internationa Sign (IS) and English. This meant that we should not rely too heavily on written English and should avoid options allowing only written chat, as in the Q/A of GLOW. Similarly, considerations regarding interpretation quality, including access to a fast and robust internet connection, were at the heart of the decision making process. This is what we describe below.

\section{FEAST structure}

Due to the pandemic, preparatory meetings of the organizing committee were held via Zoom. Members of the committee included five senior and three junior researchers who were involved at all stages of the organization. One of the members of the committee was a Deaf researcher. We additionally received help from two Ph.D. students.

\subsection{Asynchronous talks but live discussions}

We chose to adopt a hybrid format for the FEAST conference, trying to combine the strengths of both CUNY and GLOW.

Talks and posters' videos had to be asynchronous because we could not risk that connectivity issues alter an online interpretation and the watching experience. We thus asked all participants to pre-record their presentation (30 minutes for a talk, 3 minutes for a poster). The videos were then sent to the interpreter team who translated them and sent back the resulting video so that we could edit the two together. However, we did not publish the videos right away. We agreed over a "recommended watching program" and a week of publication. Videos were put online at the beginning of the conference week (see Section 3.2) and people were free to watch them right away or, following the recommended schedule, just before their dedicated Q/A live session.

One aspect that we needed to take into account when agreeing on the program was to ensure that everyone around the world would be able to participate in the live Q/A sessions, or at least, that it would be as optimal as possible. After comparing the main time zones (Japan, Hong Kong, West Coast USA, East Coast USA, Paris, Brazil...), we agreed that the 
best timespan would be between 2pm (early morning in the US, evening in Hong-Kong) to 6/7pm (noon in the US, night in Hong-Kong) Paris time. We also made sure that talks from US presenters would be put later in the day, while Asian presenters would be put earlier in the day. Poster sessions were in the middle of the day so that any presenters could participate in the discussion (see Figure 4).

\begin{tabular}{|c|c|c|c|c|c|c|c|c|}
\hline \multicolumn{4}{|c|}{ Time zones } & \multirow{2}{*}{$\begin{array}{l}\text { Monday } \\
\text { June, 22nd }\end{array}$} & \multirow{2}{*}{$\begin{array}{l}\text { Tuesday } \\
\text { June, 23rd }\end{array}$} & \multirow{2}{*}{$\begin{array}{l}\text { Wednesday } \\
\text { June, 24th }\end{array}$} & \multirow{2}{*}{$\begin{array}{l}\text { Thursday } \\
\text { June, 25th }\end{array}$} & \multirow{2}{*}{$\begin{array}{c}\text { Friday } \\
\text { June 26th }\end{array}$} \\
\hline coast & coast & France & Kong & & & & & \\
\hline $02 \mathrm{~h}$ & 04h & $09 \mathrm{~h}$ & $15 \mathrm{~h}$ & Posters on line & & & & \\
\hline 3 & 5 & 10 & 16 & Videos on line & & & & \\
\hline 4 & 6 & 11 & 17 & & & & & \\
\hline 5 & 7 & 12 & 18 & & & & & \\
\hline 6 & 8 & 13 & 19 & & & & & \\
\hline 7 & 9 & 14 & 20 & & $\begin{array}{c}\text { Talk } 1+\text { Question } \\
\text { time }=1 \mathrm{~h}\end{array}$ & $\begin{array}{c}\text { Talk } 4+\text { Question } \\
\text { time }\end{array}$ & $\begin{array}{c}\text { Talk } 7+\text { Question } \\
\text { time }=1 \mathrm{~h}\end{array}$ & \\
\hline 8 & 10 & 15 & 21 & & $\begin{array}{c}\text { Talk } 2+\text { Question } \\
\text { time }\end{array}$ & $\begin{array}{c}\text { Talk } 5+\text { Question } \\
\text { time }\end{array}$ & $\begin{array}{c}\text { Talk } 8+\text { Question } \\
\text { time }\end{array}$ & \\
\hline 9 & 11 & 16 & 22 & & $\begin{array}{l}15 \text { min lightning } \\
\text { talks Poster } \mathrm{Q} / \mathrm{A}\end{array}$ & $\begin{array}{l}\text { Dedicated Poster } \\
\text { Q/A time }\end{array}$ & $\begin{array}{c}\text { Dedicated Poster } \\
\text { Q/A time }\end{array}$ & \\
\hline 10 & 12 & 17 & 23 & & $\begin{array}{c}\text { Talk } 3+\text { Question } \\
\text { time }\end{array}$ & $\begin{array}{c}\text { Talk } 6+\text { Question } \\
\text { time }\end{array}$ & $\begin{array}{c}\text { Talk } 9+\text { Question } \\
\text { time }\end{array}$ & \\
\hline 11 & 13 & 18 & 24 & & Social time & Documentary & $\begin{array}{c}\text { Talk } 10+ \\
\text { Question time }\end{array}$ & \\
\hline
\end{tabular}

Figure 4: Illustration of the timetable we agreed upon, based on timezones.

The asynchronous talks, and the fact that we put the videos online one day before their recommended watch time, allowed participants to watch talks whenever they could, ahead of time, if the 'official' diffusion was too early or too late in their timezone.

At the end of each Q/A session, moderators also announced what was the next event in line in the program (next talk, poster session, or social event). The talks and posters' videos remained online without a time limit (unless the presenters were against it, in which case the video only stayed for a week), the Q/A sessions replays were only available for a week.

Ahead of the conference, we also provided, on the conference website, a page dedicated to explaining the whole conference process, along with video tutorials on how to ask questions such that attendants would not feel lost (see here).

The choice of this format entailed a lot of work from the committee itself. All the details of the preparatory tasks can be found here: list of tasks, or in the Appendix. 


\subsection{One website for one conference}

We decided that each talk and poster should have its dedicated page on the conference website, and that all should be accessible from the conference's program page. An example of a talk page is presented in Figure 5. The page is headed by the title of the talk, the name of the authors and their affiliations, as well as an embedded video (from our Youtube channel) that could be played directly on the website. Under the video, attendants could download both the PDF of the slides and the transcript of the video, to ease accessibility.

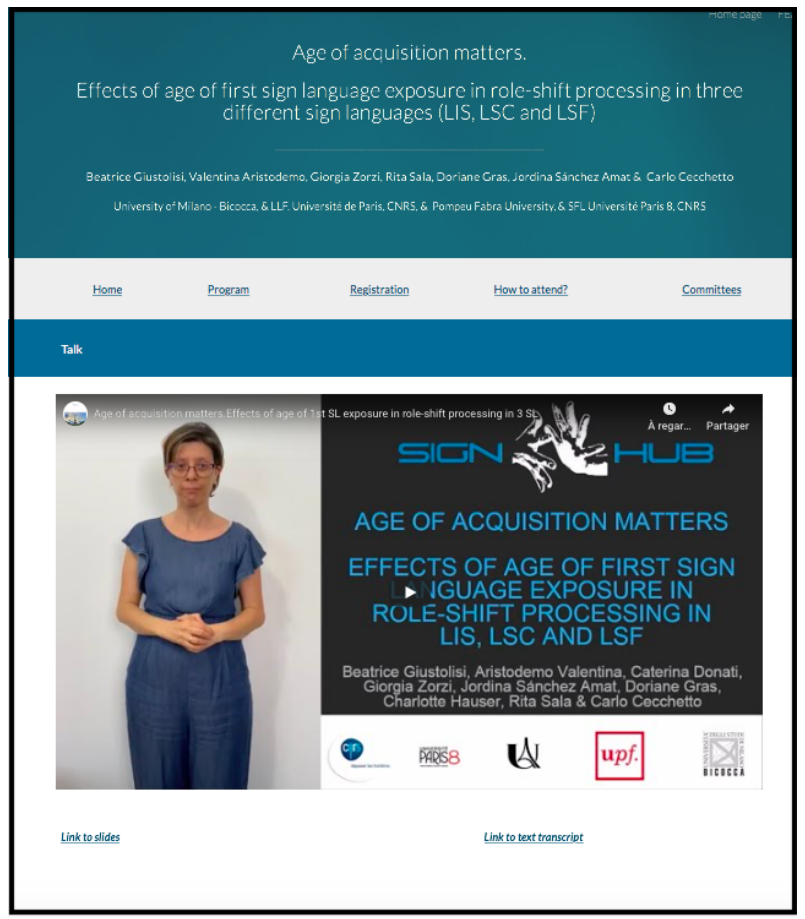

Figure 5: Example of a talk page on the FEAST website .

Posters were organized in three sessions of four posters each. They consist of a lightning talk, a 3 minute video presentation of the poster, and the PDF version of the poster itself. A montage of all four lightning talks was displayed on each poster session respective page, and the four relevant posters were accessible through clickable links underneath the video (see Figure 6). A full size example can be consulted here.

Each poster had its own dedicated page containing: 1) its own lightning talk, 2) the poster displayed in full page, 3) the link to download the poster as a PDF file, 4) the link to download the lightning talk's transcript (see again Figure 6 and here for a full-size example).

All these pages with the name of the authors, the title of the talk/poster and the place to embed the associated video, etc. were prepared two weeks before the event but remained hidden from navigation until the due date. Once edited with their translation (see the next section), all the videos were put on the conference Youtube channel, unlisted, allowing to embed the videos on the conference website. Storing the videos on Youtube also made the integration of subtitles easier and it additionally allowed us to track the number of views for each video and ensured that there would not be any issue regarding the number of people watching the videos at the same time.

On the Monday of the conference's week, all the unpublished pages were released and hyperlinks to each page were added on the program page of the conference's website. 

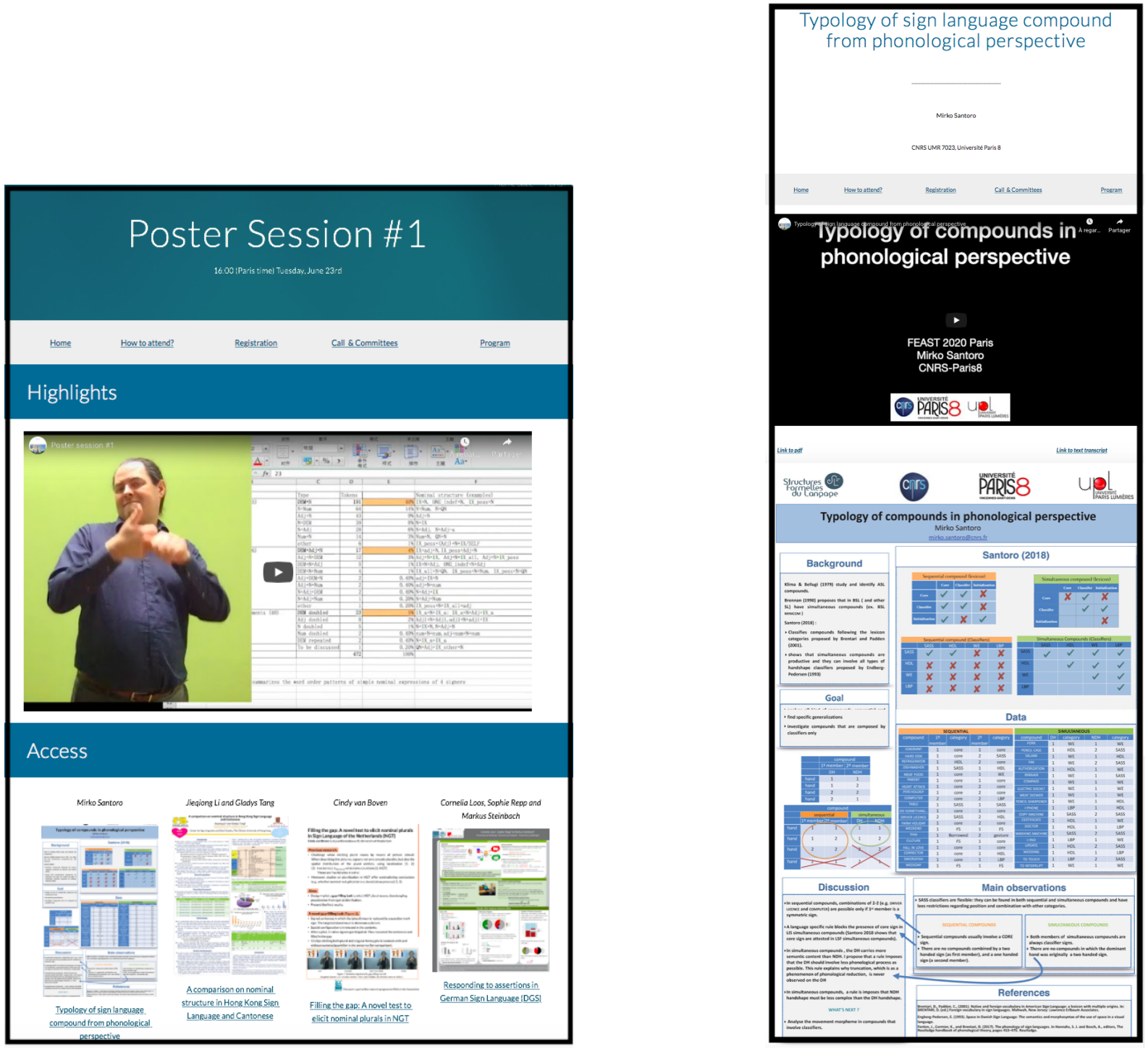

Figure 6: Example of the highlight's page, presenting each poster of a given session (left) and of a poster page (right) .

\subsection{Bilingual discussion devices}

All the talk Q/A sessions were held live on Zoom and recorded. The Zoom links of each session (1 per day) were sent by emails (see example here) to avoid Zoom-bombing. For each Zoom session, there was a staff member in charge of closing videos and sound of people not following the rules. The chair had the role of reminding people of all the rules and giving the floor to each person who had raised their hand by using the dedicated Zoom device. S/he additionally had a visual reminder always next to her/his face to ensure that the sessions' rules were known to everyone watching (see Figure 7). 


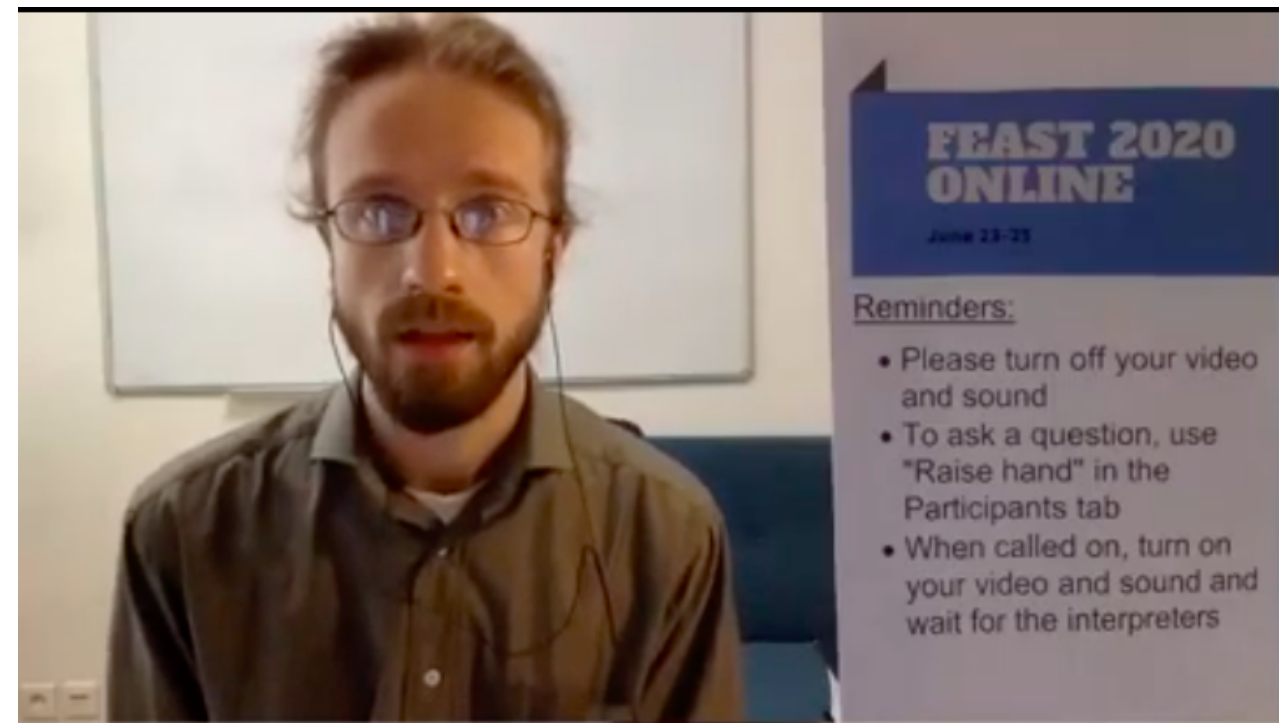

Figure 7: Chair with visual reminder of the rules, during a live zoom session.

The poster Q/A sessions were held through Skype group chats in which it is very easy to i) create a group chat ahead of time, ii) share an invitation link to that group chat and iii) send either text messages or video messages. We detail this point further in Section 4.2.2.

\section{Accessibility}

\subsection{Talk and poster videos}

One crucial requirement of FEAST is its accessibility to both speakers and signers. Since the event was now completely online we had to make sure that all of its online aspects were fully accessible to signers. Crucial information on the conference website were displayed both in English and in International Sign (IS), thanks to Mirko Santoro, a member of the organizing committee who is fluent in IS.

Due to the hybrid format of our conference, we recruited interpreters for both offline translation and online interpretation. Offline translation required to edit presenters' videos to add the videos of the interpreters' translations. Live interpretation for Q/A sessions did not require preparatory work on the organizing committee's side.

Translation of the talks and posters was realized by a team balanced in gender, with two male and two female interpreters.

To facilitate the interpreters' work and that of post-production editing, we requested that presenters record their presentation following a number of key constraints: they had to 1) leave $1 / 4$ of their slides space empty (so that interpreters' video could be later inserted, see Figure 8), 2) moderate speech and signing pace and wait a few seconds before switching to the next slide, 3) never speak/sign while displaying an example or showing a video (the examples had to be introduced and then explained but not spoken/signed over). Whenever presenters did not follow the instructions, we had to diminish the size of the slides, to ensure that the video with the interpreter had a reasonable space. Similarly, when presenters did not respect the slow pace compatible with interpretation, we had to edit the videos to add still images, so that the slide would remain displayed as long as the interpreter had not finished interpreting it. At the end of this editing procedure, all the talks and posters videos where bilingual in English and IS. 


\section{Syntactic properties of LIS}

- Italian Sign Language (LIS): SOV language

- The handshape of the classifier predicate expresses argument structure alternations

- LIS wh-questions

4. CHILD EAT WHAT

'What does the child eat?'

\section{Empty space left \\ to integrate the \\ interpreters' video}

- LIS relative clauses

5. [CHILD $\mathrm{a}$ PIZZA EAT $\left(\mathrm{PE}_{\mathrm{a}}\right)$ ] DOG BUY DONE

'The child who eats pizza has bought a dog'

Figure 8: Example of an ideal slide display.

The interaction with the interpreting team was mediated by the local organizers. When collected, the organizing committee put all the video presentations in a folder shared with the interpreters, who returned a video translation to be edited with the video presentation. We mainly used Adobe Premiere ${ }^{3}$ for video editing. When we edited the interpreters' videos, we made sure that the size of the interpreter was as big as possible, to ensure the best possible visual display of the slides' text and interpretation. We also made sure that the interpreters' eyegaze and pointing direction were coherent with their position on the slide (see Figure 9).

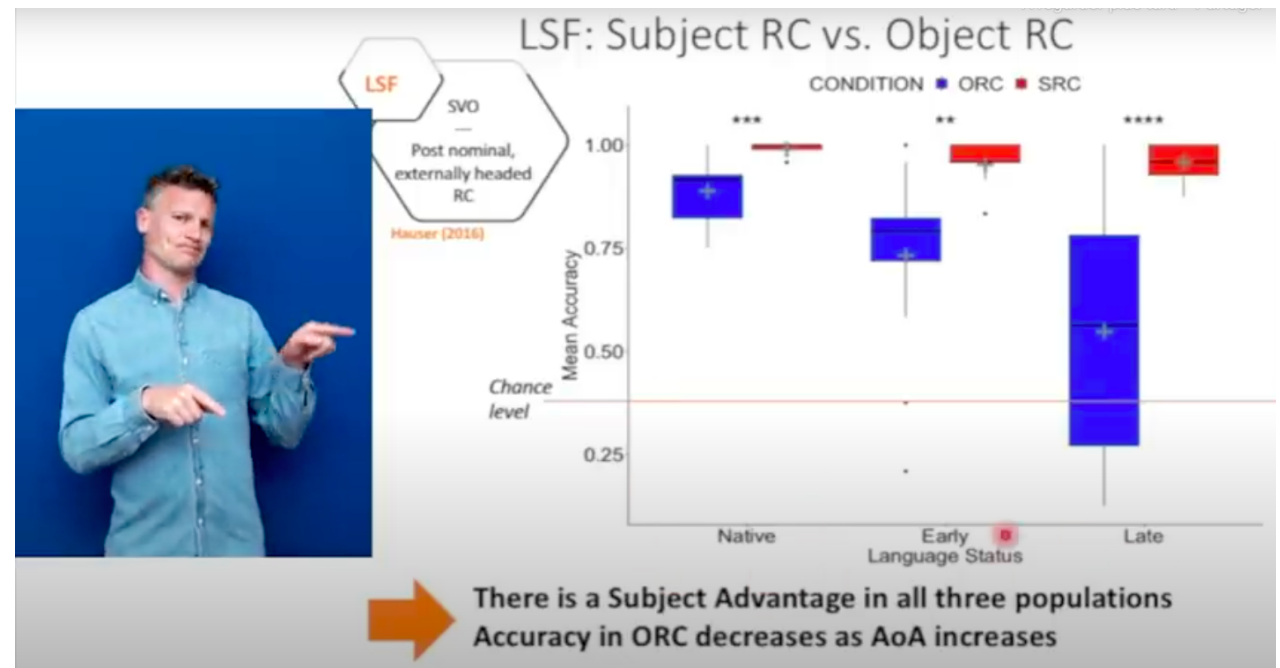

Figure 9: Example of the integration of the interpreter's video within the presentation video.

Finally, we used Otter.ai ${ }^{4}$ to create automated captions for each video. All the transcripts were sent to the presenters so that they could review them and send them back quickly.

\footnotetext{
3 adobe.com

${ }^{4}$ https://otter.ai. This is a very quick way to obtain subtitle files made from automated captions. For a 30minutes video, Otter.ai takes 5 minutes at maximum to create the captions.
} 
These transcripts were then sent to the interpreters to allow the translation process. We put a copy of the transcripts as subtitles on Youtube and also put a direct link to download them for people wishing to read them on each talk or poster's page.

\subsection{Q/A sessions}

\subsubsection{Talk $Q / A$ sessions}

From GLOW's experience, we learned that having asynchronous Q/A sessions is not that attractive or engaging for participants, so we decided to have it live, with live interpretation. On Zoom, we found that the best way to guarantee an optimal visual display was to select the "gallery view" and the option "hide participants without video". With this display, only the presenter(s), the interpreter, the person asking a question and the moderator were visible on-screen.

To avoid reducing too much the window with the interpreters, at most two presenters for each talk could have their camera on at the same time. To ensure equal accessibility and to keep track of the order of questions, questions could be asked only via the "Raise hand" Zoom option, whose location and use was explained at the beginning of each session and through a visual reminder printed by all moderators (see Figure 7 in the previous section). The chat was thus deactivated; only the hosts could use it to send general reminders to participants.

People asking questions had to unmute their sound and video by themselves, introduce their sign name, and wait for the interpreters to be ready before asking a question.

During the conference, Justine Mertz and Charlotte Hauser played the role of hosts: they launched the Zoom session, started the recording of the session, shut down videos or sounds that were unwanted and lowered hands after a question had been effectively asked. Chairs (Caterina Donati, Markus Steinbach, Jana Hosemann, Jeremy Kuhn, Carlo Cecchetto and Carlo Geraci), explained how to ask questions, how to get the best visual display on Zoom, and handled the chair person's tasks. Having live sessions was livelier and gave the feeling of a 'true' conference, since the moderator would announce the next talk/poster session or event in which attendants could participate.

The live Q/A sessions were also recorded, the videos put on Otter.ai to obtain transcripts which, after revision, were used as subtitles. The Q/A videos were embedded on each talk's webpage and stayed online for a week.

\subsubsection{Poster Q/A sessions}

Poster sessions typically have a less formal flavor than main session presentations. They are the ideal forum for more articulated exchanges between presenters and the audience. We wanted to maintain this spirit as much as possible. To obtain this, we needed to ensure: 1) that the conversations were easy to access from a technical point of view, 2) that the informal tone that is typical of in-person interactions was preserved, 3) that people reaching the discussion could be able to see the previously asked questions, 4) that English was not the only language of the exchanges, 5) that no-one would be left behind based on the language they understand. To achieve all these objectives, we chose to use Skype group chats. Skype group chats were created ahead of time, one per poster; they allowed to send text messages but also direct video messages. This last option was crucial in avoiding the hassle of recording a video, saving it somewhere on one's computer and loading it then as an attachment to a webchat. Each poster's group chat was accessible through a clickable link on the 
poster's page, making it very easy to access. You can see one example of a poster chat here: https://join.skype.com/amGwQbSB90tp.

We asked people not to launch video live conferences, because we could not provide simultaneous interpretation of four posters, and because we did not want to risk having people speaking to one another, hence excluding part of the attendants from the discussion.

At the time of the official (i.e. according to the watching program) beginning of the poster session, people were invited to watch the video of the lighting talks (put online asynchronously) and download/see the PDF version of the poster (on their respective webpage). They had then 45 minutes to go to the dedicated Skype chatroom where the poster session occurred via written chats or recorded videos in sign language. This way, the whole discussion was in principle available to all attendees. There was no moderation or chairing activities supervising Skype group chat. We only sent a general message at the end of the 45 minutes to remind people that they should go watch the next talk in the program.

Despite being unconventional, this approach had some advantages: (a) when people went to a poster chat, they could see the questions that other people had asked before they arrived (b) it served as a record for the authors of all the comments they received, (c) if participants didn't have time to see all the posters, they could take a look at the discussion later or even ask their questions in advance.

While we received remarks that the poster discussions should have been held also on Zoom, we believe that the option we found was the most accessible and egalitarian, considering the resources available. Had we gotten more funds, we would have organized Zoom group sessions with one interpreter per group to translate the questions and answers.

\section{Social events}

It is often said that coffee and lunch breaks are fully parts of a conference; this is when we build and consolidate our research network. For this reason, we tried to provide attendants with opportunities to exchange informally, like at real conferences.

This is probably the point on which we have the largest improvement margin. There were two official social events: one planned on Tuesday 23rd, at 6pm (Paris time), for which we had a shared Google sheet on which we invited people to propose their own meeting and provide the link to access it (following CUNY's model), and another which offered to watch together the premiere of the SIGN-HUB documentary "We were there... we are here" (you can watch it online at https:/ / www.sign-hub.eu/documentary).

The first event did not receive a lot of attention, the second, however, was a success. It even overloaded the maximum capacity of our Zoom session (100 people) that was held for the live introduction to the documentary. Gladly, the actual watching of the movie was on Youtube, hence presenting no maximum viewer limit.

For future conferences, we think that social events would have more chances to succeed if they are planned in-between talks, so that people can discuss after a session, while they wait for the next one. Additionally, we recommend future events to use gather.town, ${ }^{5}$ as this platform is a funny way to reproduce informal conference conversations. It is a virtual room, in which you can move away or towards other people to start a discussion (both by video and by audio media, hence allowing signed interactions as well); people too far from you cannot interact until they come closer.

\footnotetext{
${ }^{5}$ https://gather.town
} 


\section{Attendance and feedback}

\subsection{Attendance figures}

In previous FEAST editions, the number of people registered was between 50-60 on average. For this FEAST 2.0 edition, 713 people registered to the conference. We think that the vast majority did so to watch the SIGN-HUB documentary since the live Q/A sessions were attended on average by 70 people; nonetheless, since the documentary was hosted on the same platform as the talks, all the people registered have learned about the FEAST conference, which is a success in itself. Additionally, all the registered participants received the daily emails containing the whole program of the day.

180 people on average have watched the talks' videos, with a minimum of 111 and a maximum of 321 views depending on the talk. At maximum, 88 people participated simultaneously in the talks' Q/A sessions on Zoom, the minimum has been reached on the last day with 57 people connected. Replays of the Q/A sessions were viewed 15 times on average. 263 people watched the live premiere of the SIGN-HUB documentary. To this date, the documentary has been watched 947 times.

\subsection{Feedback}

Immediately after the conference ended, a survey was sent to all the registered participants to obtain anonymous feedback about the conference. Only 34 people answered among which $15 \%$ were Deaf people.

On average, participants reported to have attended around 7 out of 10 talks, and 6 associated live Q/A sessions. Regarding posters, attendants consulted an average of 7 out of 12 posters and only to 4 associated Q/A Skype group chats.

On a 6-point scale, attendants gave an average score of 5.03 regarding how much they enjoyed the conference. $91 \%$ of respondents said that the details about the conference attendance, registration and so on were either "extremely easy to find" (51\%) or "moderately easy to find" (40\%). The asynchronous talks were graded 4.65/6 regarding their liveliness and 5.47/6 regarding their accessibility. Similar results were obtained about live Zoom Q/A with a 4.8/6 mean for their liveliness and 5.31/6 for accessibility.

The answers we collected highlight that, overall, the conference met its objectives in terms of engagement and accessibility. Participants really enjoyed to have both subtitles and transcription provided for each talk and many attendants appreciated the hybrid format which allowed them to watch the talks ahead of the Q/A session.

There are a numbers of improvements that can still be made, especially regarding the poster Q/A sessions. People found this solution to be quite slow, especially when sending signed video messages, and did not like to have to use two separate live conference softwares (Zoom and Skype) within a single conference.

Regarding social events, in the future we think that it would probably be better to insert social times in-between presentations, such that people can discuss previous presentations together and would have time "blocked" in their schedule to do so.

\section{Conclusion: A take home message for future similar events}

We believe that the conference we organized could serve as a model for future online fullyaccessible events. In fact, the hybrid format could even be adopted for on-site conferences 
since it allowed interpreters to prepare the talks' translation more thoroughly while giving us time to provide high quality captioning.

In general, accessibility should not be restricted to conferences overtly addressing sign languages-related topics; it should become part of the priorities of any organizing committee to reflect on how to ensure scientific dissemination to the entire community. To do so, we recommend that all conferences should have funds dedicated to interpreting services. The asynchronous talks, edited ahead of time with translation, should follow the display and pace guidelines we issued, namely: leaving $1 / 4$ of the slide's space empty to allow interpreters' integration, having a slower pace of speech, and never talking while showing an example. We also recommend to always provide attendants with a way to download slides and transcripts of the presentations, and to use transcripts as subtitles for each video. Finally, live Q/A sessions should always come with live interpretation and, if possible, captions as well. These latter addenda are done by automatic software with little post-processing and editing effort, and do not impact research funds.

\section{Acknowledgments}

This conference would not have been possible without the financial support of the ERC Grant Orisem (PI: Philippe Schlenker), the Laboratoire de Linguistique Formelle (Université de Paris - CNRS), and Structures Formelles du Langage (Université de Paris 8 - CNRS). All our thanks also goes to the presenters, who committed to the conference and largely contributed to its success, and to the Overseas Interpreting Service team for their excellent service and adaptability.

\section{Appendix: Practical task checklist}

\section{Before the conference}

\begin{tabular}{|c|c|}
\hline Who is doing the task & Tasks which can be realized well ahead of time \\
\hline Organizing committee (OC) & $\square$ Prepare a "How to attend page" \\
\hline OC & $\square$ Prepare a program \\
\hline OC & $\square$ Create video tutorials about Q/A sessions \\
\hline OC & $\begin{array}{l}\square \text { Create a public 'Program' page on the website, to in- } \\
\text { form attendants and presenters about the conference } \\
\text { watching schedule }\end{array}$ \\
\hline OC & $\begin{array}{l}\square \text { Prepare a hidden page with the name of the talk / poster } \\
\text { and of the authors on the website }\end{array}$ \\
\hline OC & $\begin{array}{l}\square \text { If it's a poster: create a skype group chat, put the access } \\
\text { link on the dedicated hidden page }\end{array}$ \\
\hline
\end{tabular}




\begin{tabular}{|c|c|}
\hline Who is doing the task & Tasks in chronological order \\
\hline OC & $\square$ Recruit interpreters \\
\hline $\mathrm{OC}$ & $\begin{array}{l}\square \text { Send notifications to presenters and announce the con- } \\
\text { ference modalities }\end{array}$ \\
\hline Presenter $(\mathrm{P})$ & $\begin{array}{l}\square \text { Record } 30 \text { minutes presentation (for a talk) or } 3 \text { minutes } \\
\text { video (for a poster) }\end{array}$ \\
\hline $\mathrm{P}$ & $\begin{array}{l}\square \text { Make sure } 1 / 4 \text { of the slide is empty, either on the left } \\
\text { or on the right side of the slides and keep the same side } \\
\text { across slides }\end{array}$ \\
\hline $\mathrm{P}$ & $\begin{array}{l}\square \text { Make sure to leave } 2 \text { seconds without talking at the end } \\
\text { of each slide }\end{array}$ \\
\hline $\mathrm{P}$ & $\begin{array}{l}\square \text { Make sure that you don't show video examples while } \\
\text { talking }\end{array}$ \\
\hline $\mathrm{P}$ & $\begin{array}{l}\square \text { Send your video presentation and your slides in PDF } \\
\text { format to the organizing committee }\end{array}$ \\
\hline $\mathrm{OC}$ & $\begin{array}{l}\square \text { Put video on Otter.ai and export transcript as a subtitle } \\
\text { file }\end{array}$ \\
\hline $\mathrm{OC}$ & $\begin{array}{l}\square \text { Send transcript to presenters asking them to review it, } \\
\text { in the same email, put the interpreters in copy such that } \\
\text { they can discuss directly afterwards. }\end{array}$ \\
\hline $\mathrm{P}$ & $\square$ Correct transcript and send it back \\
\hline OC & $\begin{array}{l}\square \text { Send video presentation to interpreters along with the } \\
\text { transcript and the slides }\end{array}$ \\
\hline Interpreters (I) & $\square$ Record translations \\
\hline I & $\begin{array}{l}\square \text { Send the translation videos to the organizing commit- } \\
\text { tee }\end{array}$ \\
\hline OC & $\begin{array}{l}\square \text { Edit the interpreter's video within the talk/poster } \\
\text { videos }\end{array}$ \\
\hline OC & $\begin{array}{l}\square \text { Put the video on Youtube, tick the option "private" to } \\
\text { avoid the video to be referenced online }\end{array}$ \\
\hline OC & $\square$ Add the transcript as a subtitle file to the Youtube video \\
\hline OC & $\begin{array}{l}\square \text { Embed the video on the talk's page you prepared. Add a } \\
\text { link to download the transcript if needed, and another to } \\
\text { download the slides of the talk. }\end{array}$ \\
\hline
\end{tabular}




\begin{tabular}{|c|l|}
\hline OC & $\square$ Repeat for as many talks as necessary \\
\hline OC & $\begin{array}{l}\square \text { Export posters as png files and embed them on each } \\
\text { dedicated poster page, under the link to access the skype } \\
\text { group chat }\end{array}$ \\
\hline OC \\
poster session
\end{tabular}

\section{During the conference}

\begin{tabular}{|c|l|}
\hline Who is doing the task & Tasks in chronological order \\
\hline OC & $\begin{array}{l}\square \text { On day -1, activate all the hidden pages (talk, posters } \\
\text { and poster sessions) }\end{array}$ \\
\hline OC & $\begin{array}{l}\square \text { Replace the program page by the one with the clickable } \\
\text { links }\end{array}$ \\
\hline OC & $\begin{array}{l}\square \text { Send an email to registered participants and presen- } \\
\text { that the conference shall officially start the next day }\end{array}$ \\
\hline OC & $\begin{array}{l}\square \text { On day } 1, \text { send the email containing the Zoom link of } \\
\text { the day }\end{array}$ \\
\hline P, I \& Chair Person (CP) & $\square$ At your slot, connect to the Zoom session \\
\hline OC & $\square$ At each slot, connect to the Zoom session \\
\hline OC & $\square$ Start recording the Q/A session \\
\hline
\end{tabular}




\begin{tabular}{|c|c|}
\hline $\mathrm{CP}$ & $\begin{array}{l}\square \text { Do all the announcements regarding recording, how to } \\
\text { ask questions, and how to obtain the best visual display }\end{array}$ \\
\hline OC & $\begin{array}{l}\square \text { If needed, shut down videos and mics of participants } \\
\text { not asking questions }\end{array}$ \\
\hline $\mathrm{CP}$ & $\begin{array}{l}\square \text { Give the floor to participants in the order they raised } \\
\text { their hands }\end{array}$ \\
\hline OC & $\begin{array}{l}\square \text { Lower the hands of participants who have asked their } \\
\text { question }\end{array}$ \\
\hline $\mathrm{CP}$ & $\begin{array}{l}\square \text { At the end of the session, announce the next event } \\
\text { (Talk, poster or social event) and when to connect again } \\
\text { to Zoom }\end{array}$ \\
\hline $\mathrm{OC}$ & $\square$ Close the meeting for everyone \\
\hline $\mathrm{OC}$ & $\square$ Save the Q/A video \\
\hline OC & $\begin{array}{l}\square \text { Put the Q/A video on Otter.ai, export the result as a sub- } \\
\text { title file }\end{array}$ \\
\hline OC & $\square$ Correct the transcript \\
\hline OC & $\begin{array}{l}\square \text { Put the Q/A video and its transcript on Youtube in pri- } \\
\text { vate mode }\end{array}$ \\
\hline $\mathrm{OC}$ & $\square$ Embed the Q/A video on the page's talk \\
\hline $\mathrm{OC}$ & $\square$ Add a link to download the transcript \\
\hline
\end{tabular}

\section{After the conference}

\begin{tabular}{|c|l|}
\hline Who is doing the task & Tasks in chronological order \\
\hline OC & $\square$ Remove Q/A videos from the website (after two weeks) \\
\hline OC & $\begin{array}{l}\square \text { Remove videos from talks if presenters did not want } \\
\text { them to stay online }\end{array}$ \\
\hline OC & $\square$ Send a feedback survey to attendants \\
\hline
\end{tabular}

